\title{
The Planning, Implementation, and Movement of an Academic Library Collection
}

\section{Donna Lee Kurkul}

Brief reviews of significant literary contributions in library collection movement purport the examination of the means elected by one medium-sized academic library, the William Allan Neilson Library, Smith College, Northampton, Massachusetts, to plan, supervise, and implement book relocation of its 682,810-volume collection throughout library construction and renovation until its completion. Planning the final movement and locations of the total collection fostered the development of mathematical formulas, the application of which proved effective for space and sequence distribution of book collections at Neilson Library. The effectiveness of standardized book collection movement rates and the efficiency of the production operation system of movement implementation are reinforced by statistics on manpower, time, and cost requirements.

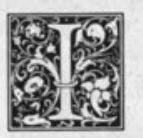

$\mathrm{n}$ a library the movements of a book collection, of book sequences, or of individual volumes within a collection are constant characteristics of stack management. Besides the normal movement due to book circulation and book returns for reshelving, several factors predetermine the forever-changing configuration of book placement on shelves within sections within ranges. A library's acquisitions rate necessitates growth space; withdrawal of obsolete materials and multiple copies creates available space. Collections of infrequently used books can be relegated to storage to create space, and conversely, books in storage may be resurrected for collection integration, which demands space. In libraries where books exist in two classification systems, books can be reclassified, leaving space vacant in one area and occupying space elsewhere. Then again, construction may be undertaken for additional space or better space utilization. But, for whatever reason books are moved, space is an unpredictable and problematic variable intrinsic to stack management.

Many articles offer descriptive accounts about newly constructed libraries and recent renovations and/or additions to existing library buildings; such literature provides planning and design alternatives in housing facilities for service points, spatial arrangement of seating, lighting, stack layout, and so forth. A review of Library Literature evidences a paucity of information on the methodology and logistics planning, implementation, and control of the physical relocation or "shifting" of book collections before, during, and after construction renovation and phasing. Only a few noteworthy contributions have satisfactorily chronologized such analytical methods.

Yet, comparatively speaking, one British librarian, A. E. Lumb, hints to the international perspective from which American literature on moving libraries and their collections may be viewed. "Moving

Donna Lee Kurkul is stack supervisor, William Allan Neilson Library, Smith College, Northampton, Massachusetts. 
a library from one or more buildings to another," he says, "is an all-around exercise in librarianship, comprising planning, organization, personnel management, measurements and statistics, work study and systems analysis, yet the published literature includes very little written in the United Kingdom, and a predominance of United States contributions. ${ }^{11}$ Lumb "attempts to provide a practical guide, in summary form, covering all aspects of a library removal" ${ }^{2}$ he neglects, however, to give examples of the types of calculations he alludes to. Nevertheless, his sixty-fiveitem bibliography of literature from 1930 to 1969 does include articles that provide such calculations.

Undoubtedly, the most substantial documentation of such efforts is represented by William H. Kurth and Ray W. Grim in their 220-page book Moving a Library. Their text describes in detail the technique and procedural aspects pertaining to Kurth and Grim's planning and direction of the 1962 sixty-day move of the millionplus volumes of the National Library of Medicine to its new location in Bethesda, Maryland. The majority of the collection was moved from "downtown Washington, fourteen miles away; a smaller but significant part had to be moved from Cleveland. ${ }^{\prime \prime 3}$ Kurth was also responsible "for the planning and direction of the Library of the University of California at Los Angeles move in June-August 1964, a major operation involving some 800,000 volumes (and the shifting of some 100,000 others in the old building)." Kurth and Grim assess "the factors with which most libraries have to cope" during "their moving operations. ${ }^{15}$ Accounts of the NLM and UCLA libraries' moves demonstrate the applicability of Kurth and Grim's principles on moving. Additionally, the variety of figures and tables, the statistical appendix, "which provides background and analysis of the technique of measurement," ${ }^{\prime 6}$ and the specimen moving contracts constitute the best reference for librarians of libraries on the move.

Another equally valuable research project on collection movement, entitled Moving Library Materials (1965), is by Peter Spyers-Duran. ${ }^{7}$ His analysis and study is not limited by library type or collection size, and similar to Lumb, he includes a thirty-one-year-span bibliography (1930$61)$. Both the time and costs of movement collected by his survey of twenty-nine libraries might be of interest to librarians comparing collection movement costs of the late 1950s and early 1960s with those available from the time/cost study of the Smith College Library move. The SpyersDuran project unquestionably attests that libraries, twenty years ago, did record data on their collection movement.

Two other librarians representing the 1960s literature about collection movement are Matt Roberts and Donald P. Hammer. Although less thorough than Kurth and Grim and Spyers-Duran, each concisely and comprehensively outlines specific moving operations, and each furnishes some calculations for those moves. ${ }^{8}$ The research of these librarians is still timely and useful. Its existence may explain the exiguity of literature on collection movement between the early 1970 s and the present.

Given the status of collectionmovement-related literature, the following account proffers to share with library communities the methodology, logistics, and time/cost study of the planning, implementation, and movement of the Smith College Library collection into its newly constructed and renovated facility.

\section{THE WILLIAM ALLAN NEILSON LIBRARY COLLECTION MOVEMENT}

It was known as early as 1973 that future plans for Neilson Library would include a mass construction and renovation project to be initiated within the next six years. In 1975 an analysis of existing shelf-growthspace capacity evidenced that available space was fast diminishing for the annual increase in the number of books on the LC collection's shelves. The growth-space requirements for the LC collection had approached the long-term projected capacity intended by the building's expansion in 1962. Shelves of LC books, once twothirds empty, grew to eleven-twelfths full. It was therefore necessary to plan enough growth space for the LC collection until 
the renovations and new additions became reality.

The Dewey portion of Neilson's collection then comprised approximately 15,000 shelves of books housed in twelve wings of the library. Many of the 15,000 , thirtyfive-inch-wide shelves were occupied with only a quarter, a third, or a half of the books they could contain. A shelf count of the closed, nongrowing, Dewey collection, ascertained during summer when most books are on their shelves, indicated that the functional space requirements to house it called for a mass compaction of books to absorb the empty space left by gradual reclassification of Dewey to LC and withdrawals of obsolete materials. The Dewey books were gradually consolidated into eight wings by 1977 .

Then, in 1978, the LC collection of monographs, folios, periodicals, and the documents collection were shifted and expanded into the four empty wings to maintain adequate space for projected collection growth throughout construction. During this same shifting period, many small collections, e.g., academic department studies in the library, books in temporary library storage, were integrated into the open-stack collection; other small collections, e.g., locked-stack area and the bibliography area, were relocated; and, lastly, several collections, e.g., withdrawals for book sale and books for future cataloging, were boxed in cardboard book-moving cartons ( 24 inches by 12 inches by $11^{1 / 4}$ inches). As books were boxed, shelf by shelf, the boxes were numbered in order and their contents labeled. Six hundred such book-moving cartons were trucked by Physical Plant personnel to an unused, vacant campus building. An on-site sketch of the numbered box layout and box content made materials accessible to anyone needing them.

Simultaneous to the library's vast book movements was the first phase of construction, initiated in late 1978; it entailed building two additions to the library, one on either end, south and north. As these additions neared completion, phase two of the building program would begin renovation of the existing library building interior. Fall of 1979 set the stage for the preparation of plans to vacate the "old Neilson core" of its books; the new south and north additions were in the final stages of being readied for book occupancy. To vacate the core for renovation, approximately 10,500 shelves of books were relocated in the summer and fall of 1980 to their temporary locations in the stack areas of the completed south and north additions to the library. These movements affected the shift plans, schedules, floor plans, and directions submitted by the stack supervisor to the college librarian and circulation department librarian in May 1980.

These preliminary stages of book movement at Neilson Library between 1975 and 1980 satisfied the library's need for interim collection storage until the building in its entirety was ready for both book and people occupancy in January of 1982 . The margin of error in the calculation and projection for the shifts was negligible, and in actuality the shifting proceeded smoothly and efficiently. The removal of books from the building's center was done by ten student assistants and four Physical Plant personnel; this combination of workers enabled both day and night book shifting. Books were moved on ten metal book trucks (total cost: \$1,289), purchased expressly for book moving, and to be designated for shelving purposes after completion of the collection move; the library's standard-length wooden book trucks (30.5 inches long), regularly used for shelving purposes, could not accommodate a full 35-inch shelf of books, as did the new metal trucks used for shifting.

Access to the collection throughout these shifts and the final collection movement was not impeded; some patrons actually were amazed to be able to retrieve sought-after materials from book trucks in transit. As stack areas of book sequences were relocated into different areas, new patron access routes were continually reestablished, and updated directories of book locations were posted daily at the circulation and reference desks. Accurate records were maintained for each move; the moving experiences and data of these previous shifts provided copious statistics on manpower, time, and budgetary re- 
quirements, which were in turn utilized by the stack supervisor to calculate, plan, and implement the project completion for the permanent location of the collection's sequences of 682,810 volumes in the finished Neilson Library.

Collection movement at Neilson had always been implemented in a shelf-byshelf book truck loading and unloading method, and this same method, performed by student assistants under the stack supervisor's direction, was chosen for the final movement of the whole collection.

Before an entire collection can be moved, certain criteria must be known and several steps must be followed via analysis of the existing collection. A chart should diagram the current call number sequences in each level and area of the building, as well as the number of shelves occupied by each sequence (see table 1); this also provides an accurate total number of shelves to be moved. Next, a chart must be provided, usually by the architects, for the count of available book-stack shelf capacity after construction/renovation (see table 2); this chart lists both the level and area counts of available shelves and the total numbers of available shelves at seven per section. The architects can also supply the building floor plans to facilitate the mapping and shelf counting of sequence distribution. The information from the charts and floor plans advanced the application of elementary algebraic principles for mathematical formulas, first, for the call number sequence distribution for the library's collection and, second, for the collection movement phasing to attain the sequence relocations (see table 3).

Calculating and deciding what collection sequences to distribute where is timeconsuming and tedious. Optional placement of collection types, e.g., Dewey collection, LC monographs, LC periodicals, etc., can be qualified or disqualified for spatial accommodation by a feasibility of options study. At Neilson Library, for example, it would have been aesthetically desirable for the closed, older Dewey collection to be situated below ground level, and it would have been convenient for the more recent $\mathrm{LC}$ collection to be on upper levels. But the feasibility of options studies proposed a more desirable alternative opting a maximum long-range plan for collection placement.

Feasibility of options study 1 , utilizing formula 1 (see table 4), proved that the combined placements of the Dewey collection's 11,989 shelves on the 17,801 available shelves of levels B and A and of the LC monograph collection's 4,334 shelves on the 9,121 available shelves of level 3 would result in the Dewey collection's occupying only 67.35 percent of available space. Applying formula 2, this would mean filling 16.6 inches of space per shelf in all seven-shelf sections for the LC monographs; with only half-shelves available for acquisitions growth-space, the shelves would be filled in about three to four years. An explanation of elementary algebraic principles can be found in appendix $A,{ }^{9}$ and an explanation of the application of algebra in formulas 1 and 2 can be found in appendix B.

The second feasibility of options study, which applied formulas 1 and 2 to the combined placements of the Dewey collection on levels 3 and 4 and of the LC monographs on levels $B$ and $A$, resulted in a 93.45 percent space occupation by Dewey, and 24.97 percent space occupation by LC monographs. The remaining 6.55 percent of space, or 840 shelves, for Dewey was distributed to shelving areas and to additional space for some very full shelves. Formula 2 showed that for LC monographs only 8.74 inches per shelf need be filled; this means a more desirable three-quarters-empty shelves for acquisitions growth-space. In both studies it was determined that the LC periodicals could be contained for fifteen years in three areas of level 2. The documents collection would remain on level 2 and later be expanded. Other smaller collections, e.g., newspapers, folios, Dewey oversize materials, locked stack, and microforms, were commodious to the building's core area.

Once establishing the placement of collection types, in this case, those preferred in feasibility of options study 2 , the next step is determining the number of shelves of each collection's sequences by area 
TABLE 1

CALL NUMBER SEQUENCE LOCATION AND OCCUPIED SHELF-COUNT PRECEDING FINAL COLLECTION MOVEMENT

\begin{tabular}{|c|c|c|c|c|}
\hline Level and Area & $\begin{array}{l}\text { Call Number } \\
\text { Sequence }\end{array}$ & $\begin{array}{l}\text { Occupied } \\
\text { Shelves }\end{array}$ & $\begin{array}{l}\text { Occupied Oversize } \\
\text { Shelves* }\end{array}$ & $\begin{array}{c}\text { Total Occupied } \\
\text { Shelves }\end{array}$ \\
\hline Level 4, west pavilion & $950-999$ & 982 & 4 sections or 28 shelves & 1,010 \\
\hline Level 4, north pavilion & $350-799$ & 1,774 & 8 sections or 56 shelves & 1,830 \\
\hline Level 3, west pavilion & $880.8-949$ & 1,745 & 7 sections or 49 shelves & 1,794 \\
\hline Level 3, north pavilion & $301.15 S-349$ & 1,839 & 2.5 sections or 17 shelves & 1,856 \\
\hline Level 3, north addition & $\begin{array}{l}\text { folio A-Z } \\
\text { theses }\end{array}$ & & $\begin{array}{l}65 \text { sections or } 455 \text { shelves } \\
5 \text { sections or } 35 \text { shelves }\end{array}$ & $\begin{array}{r}455 \\
35\end{array}$ \\
\hline & $\begin{array}{l}\text { newspapers } \\
\text { current }\end{array}$ & & 68 sections or 476 shelves & 476 \\
\hline & periodicals & $476 t$ & & 476 \\
\hline Level 2, south addition & $835 \mathrm{H}-880.7$ & 1,889 & 5 sections or 35 shelves & 1,924 \\
\hline Level 2, north pavilion & $000-301.15 R$ & 1,839 & 3 sections or 21 shelves & 1,860 \\
\hline Level 2, north addition & $\begin{array}{l}\text { documents } \\
\text { PR2753-Z }\end{array}$ & $\begin{array}{r}1,108 \\
721\end{array}$ & & $\begin{array}{r}1,108 \\
721\end{array}$ \\
\hline Level A, south addition & $800-835 G$ & 1,925 & 5 sections or 35 shelves & 1,960 \\
\hline Level A, north pavilion & HD31-PR2752 & 1,914 & & 1,914 \\
\hline Level A, north addition & A-HD30 & 1,699 & & 1,699 \\
\hline Level B, north pavilion & $\begin{array}{l}\text { per } \mathrm{DL}-\mathrm{PA} \\
\text { per } \mathrm{PB}-\mathrm{Z}\end{array}$ & $\begin{array}{l}2,085 \ddagger \\
1,834 \ddagger\end{array}$ & & $\begin{array}{l}2,085 \ddagger \\
1,834 \ddagger\end{array}$ \\
\hline Level B, north pavilion & per A-DK & $1,918 \ddagger$ & 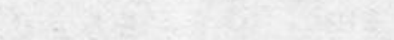 & $1,918 \ddagger$ \\
\hline $\begin{array}{l}\text { In storage } \\
\text { TOTAL }\end{array}$ & locked stack & $\begin{array}{r}154 \\
23.902\end{array}$ & & $\begin{array}{r}154 \\
109\end{array}$ \\
\hline & & 23,902 & 172.5 sections or 1,207 shelves & 25,109 \\
\hline
\end{tabular}

*To facilitate calculations for space relocation requirements, oversize shelves occupying 4-, 5-, or 6-shelf sections were converted to 7-shelf-per-section standard. tAt 9 shelves per section.

$\ddagger$ These counts include the minimum of 10 years' growth space per title.

TABLE 2

COUNTS OF AVAILABLE BOOK-STACK SHELVES POST-CONSTRUCTION/RENOVATION

\begin{tabular}{|c|c|c|c|c|c|c|c|}
\hline Area & $\begin{array}{c}\text { Level } \\
\text { B }\end{array}$ & $\begin{array}{c}\text { Level } \\
\text { A }\end{array}$ & $\begin{array}{c}\text { Level } \\
1\end{array}$ & $\begin{array}{c}\text { Level } \\
2\end{array}$ & $\begin{array}{c}\text { Level } \\
3\end{array}$ & $\begin{array}{c}\text { Level } \\
4\end{array}$ & Total \\
\hline South addition & 0 & $1,932 \quad(1,320)$ & 0 & 2,940 & 1,036 & 0 & 5,908 \\
\hline South pavilion & $1,701(1,160)^{*}$ & 0 & 0 & 1,295 & 1,715 & 0 & 4,711 \\
\hline West pavilion & $2,604 \quad(1,801)$ & $(1,570)$ & 0 & 0 & 2,828 & 1,764 & 9,478 \\
\hline Core pavilion & $1,260 \quad(900)$ & 1,260 & 0 & 616 & 0 & 728 & 3,864 \\
\hline North pavilion & $1,946 \quad(1,390)$ & $(1,390)$ & 0 & 1,792 & 1,946 & 1,946 & 9,576 \\
\hline North addition & $1,792 \quad(1,180)$ & $(1,180)$ & 0 & 1,792 & 1,596 & & 6,972 \\
\hline Total & 9,303 & 9,212 & 0 & 8,435 & 9,121 & 4,438 & 40,509 \\
\hline
\end{tabular}

*Parenthesized counts are standardized at 5 shelves per section; all other counts are standardized at 7 shelves per section. 
TABLE 3

COLLECTION-MOVEMENT PHASING OF SEQUENCE DISTRIBUTION

\begin{tabular}{|c|c|c|c|c|}
\hline Level and Area & $\begin{array}{l}\text { Call Number } \\
\text { Sequence }\end{array}$ & $\begin{array}{c}\text { Shifting } \\
\text { Phase No. } 1\end{array}$ & $\begin{array}{c}\text { Shifting } \\
\text { Phase No. } 2\end{array}$ & $\begin{array}{c}\text { Shifting } \\
\text { Phase No. } 3\end{array}$ \\
\hline Level 4, core pavilion & newspapers & newspapers (c) ${ }^{\star}$ & & \\
\hline Level 4, north pavilion & $940-999$ & $973.72-999(u)$ & $940-949(u)$ & $950-973.71(\mathrm{c})$ \\
\hline Level 4 , west pavilion & $850-939$ & & $850-880.7(\mathrm{u})$ & $880.8-939$ (c) \\
\hline Level 3, north addition & $830-849$ & & $830-849$ (c) & \\
\hline Level 3, north pavilion & $600-829$ & $600-799(u)$ & $800-825 F .5(u)$ & $825.6-829(c)$ \\
\hline Level 3 , west pavilion & $330-599$ & $330-334.25(u)$ & $345.13-599(\mathrm{u})$ & $334.26-345.12$ (c) \\
\hline Level 3, south pavilion & $190-329$ & $190-329$ (c) & & \\
\hline Level 3 , south addition & 000-189 & $000-189$ (c) & & \\
\hline Level 3 , core pavilion & microforms & microforms (c) & & \\
\hline Level 3, east pavilion & current periodicals & current per (c) & & \\
\hline Level 2 , north addition & documents & & & documents (c) \\
\hline Level 2 , north pavilion & LC periodicals $\mathrm{P}-\mathrm{Z}$ & LC per $\mathrm{P}-\mathrm{Z}$ (c) & & \\
\hline Level 2 , south pavilion & LC periodicals $\mathrm{HE}-\mathrm{N}$ & LC per HE-N (c) & & \\
\hline Level 2 , south addition & LC periodicals A-HD & LC per DS-HD (u) & & LC per A-DR (c) \\
\hline Level 2 , core pavilion & $\begin{array}{l}\text { locked stack } \\
\text { LC monographs }\end{array}$ & locked stack (c) & & \\
\hline Level $\mathrm{A}$, north addition & PS-Z & & PS-Z (c) & \\
\hline Level A, north pavilion & PQ-PR & & & PQ-PR (c) \\
\hline Level A, west pavilion & P-PN & & & P-PN (c) \\
\hline Level $\mathrm{A}$, south addition & $\mathrm{K}-\mathrm{N}$ & & & $\mathrm{K}-\mathrm{N}(\mathrm{c})$ \\
\hline Level $\mathrm{A}$, core pavilion & $\begin{array}{c}\text { folio, theses } \\
\text { Dewey oversize }\end{array}$ & $\begin{array}{r}\text { folio, theses } \\
\text { Dewey oversize }\end{array}$ & & \\
\hline Level B, north addition & $\mathrm{J}$ & & & $\mathrm{J}(\mathrm{c})$ \\
\hline Level B, north pavilion & G-H & & $\mathrm{G}-\mathrm{H}(\mathrm{c})$ & \\
\hline Level B, core pavilion & E-F & & E-F (c) & \\
\hline Level B, west pavilion & C-D & & C-D (c) & \\
\hline Level B, south pavilion & A-B & & $\mathrm{A}-\mathrm{B}(\mathrm{c})$ & \\
\hline
\end{tabular}

-The completed $(c)$ or uncompleted $(u)$ relocation of the call number sequence designated for the area during each shifting phase number. 
TABLE 4

COLLECTION-MOVEMENT FORMULAS FOR COLLECTION SEQUENCE DISTRIBUTION

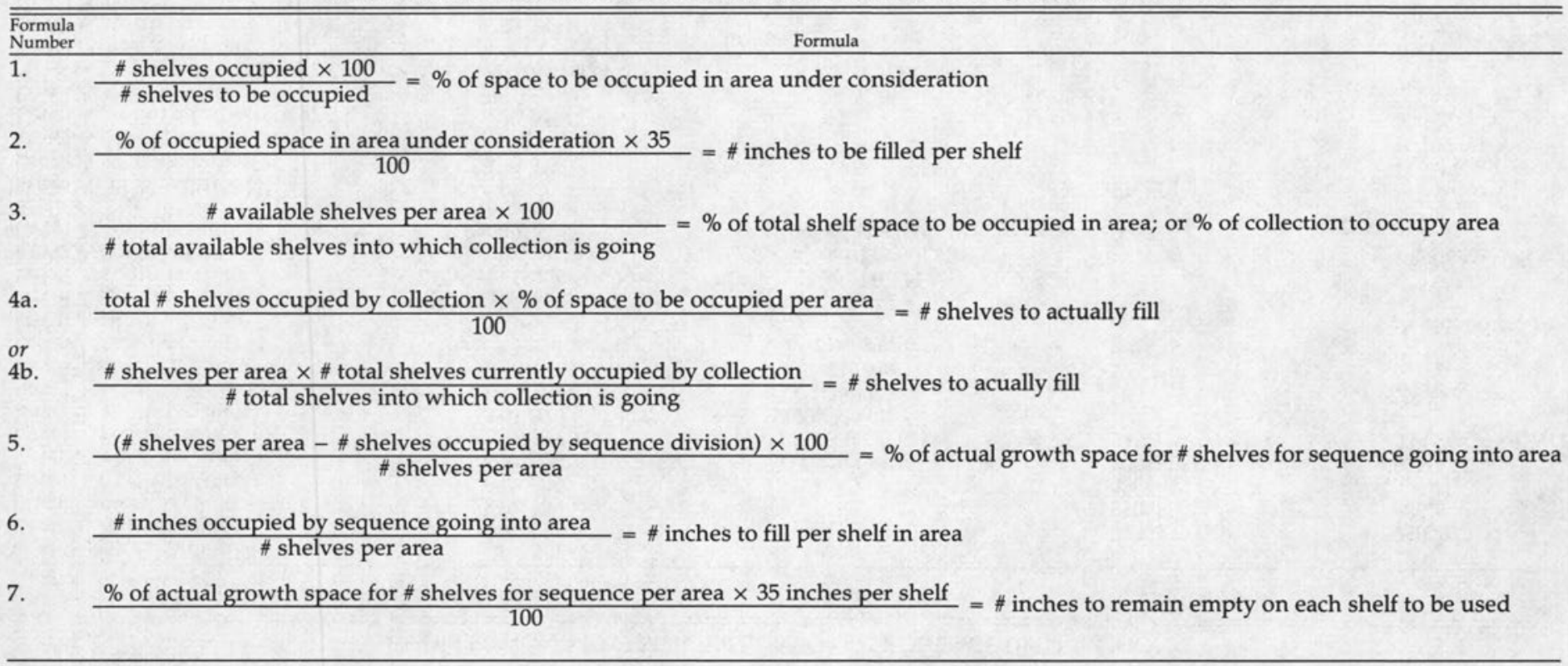


within level. All sequences were requested by the college librarian to proceed in a south to north arrangement, or left to right as you enter the library building; book stacks were constructed in a west to east configuration. Distribution of book sequences ideally requires even call number divisions between levels and areas, as well as maintaining an average percentage of collection growth-space per sequence per area for the LC monographs.

Dividing the Dewey collection into logical sequence and subject divisions for an area was simpler than doing so for the LC collection. In Dewey, for example, the 000 s would start in level 3 , south addition. The number of available shelves, 1,036 (see table 2), was subtracted from the 1,839 occupied shelves for sequence $000-301.15 \mathrm{R}$ (see table 1); counting in reverse, the difference of 803 shelves determined a sequence division at the end of call number 189 . Therefore $000-189$ would be moved from level 2, north pavilion, into level 3, south addition. And so it follows, the remaining 803 shelves (190-301.15R, level 2, north pavilion), plus 586 shelves (301.15S-329, level 3, north pavilion), were moved into level 3 , south pavilion. The 1,715 available shelves in level 3, south pavilion, minus the 1,389 to be occupied by $190-329$, left 326 shelves for space dispersal in full-shelf areas and for the shelving area. The remaining sequence of Dewey from 330-999 was likewise calculated, and each move from and to an area was illustrated on floor plans (see figure 1). When a number of shelves to be occupied in an area with a logical break exceeded the number of available shelves, eight shelves per section (instead of seven per section) were dispersed throughout the number of book-stack ranges necessary to accommodate the additional number of shelves.

The nine areas of levels B and A, as indicated in table 2, have a total of 17,355 available shelves into which the LC monograph collection of 4,334 shelves of books would be dispersed. Since the LC monographs would begin with LC sequence $\mathrm{A}$ in level B, south pavilion, this area with 1,701 available shelves illustrates the application of formula 3 (see table 4 ) to obtain the percentage of shelf space to be occupied in an area: 1,701 shelves $\times$ 100) $/ 17.355$ shelves $=9.8 \%$ (percentage of shelf space to be occupied in area, or of LC monograph collection to occupy arealevel $\mathrm{B}$, south pavilion) $(100 \%-9.8 \%=$ 90.2 growth space estimated). Application of formula 3 resulted in a range of 9.8 percent to 15 percent of total occupied shelf space for each of the nine areas of levels B and $A$; these percentages indicated expansion capacity for the LC monographs ranging between 85 and 90 percent of total available shelf space.

Either formula $4 \mathrm{a}$ or $4 \mathrm{~b}$ can be applied to indicate the number of shelves to be filled in an area, as illustrated for level B, south pavilion: $(4 \mathrm{a})(4,334$ shelves $\times 9.8 \%) / 100$ $=424$ shelves to fill; $(4 \mathrm{~b})(1,701$ shelves $\times$ 4,334 shelves) $/ 17,355$ shelves $=424$ shelves to fill. This step was repeated for the other eight available areas of levels B and $\mathrm{A}$.

The numbers of shelves to fill in areas guided the count for actual numbers of shelves for the sequences in the nine areas for LC monographs. Counting forward into $\mathrm{LC}$ sequence $\mathrm{A}$, to begin in level B, south pavilion, it was found that LC sequence A only had 102 shelves; the counting continued through sequence B. LC sequence A through B had 494 shelves, 70 over the 424 calculated (above). Formula 5 was used to evaluate the growth-space percentage difference resulting from the 70 additional shelves in order to divide the sequence at the end of $B$, before $C:[(1,701$ shelves - 494 shelves) $\times 100] / 1,701$ shelves $=70.95 \%$ (actual growth space for sequence A and B, going into level B, south pavilion). There would only be a 19.25 percent difference from the 90.2 percent estimated growth space. Repetition of formula 5 for the other eight areas of levels B and A resulted in the sequence distribution for LC monographs shown in table 3, with an actual average of growth capacity between 70.95 and 74.38 percent, the latter being equivalent to the 75 percent growth space for LC monographs projected in feasibility study 2 . With as little as 30 percent of a shelf being occupied, a collective decision promoting convenient patron access determined that only 
LEVEL 2

SOUTH

NORTH

Addition

Pavilion

Core

Pavilion

Addition

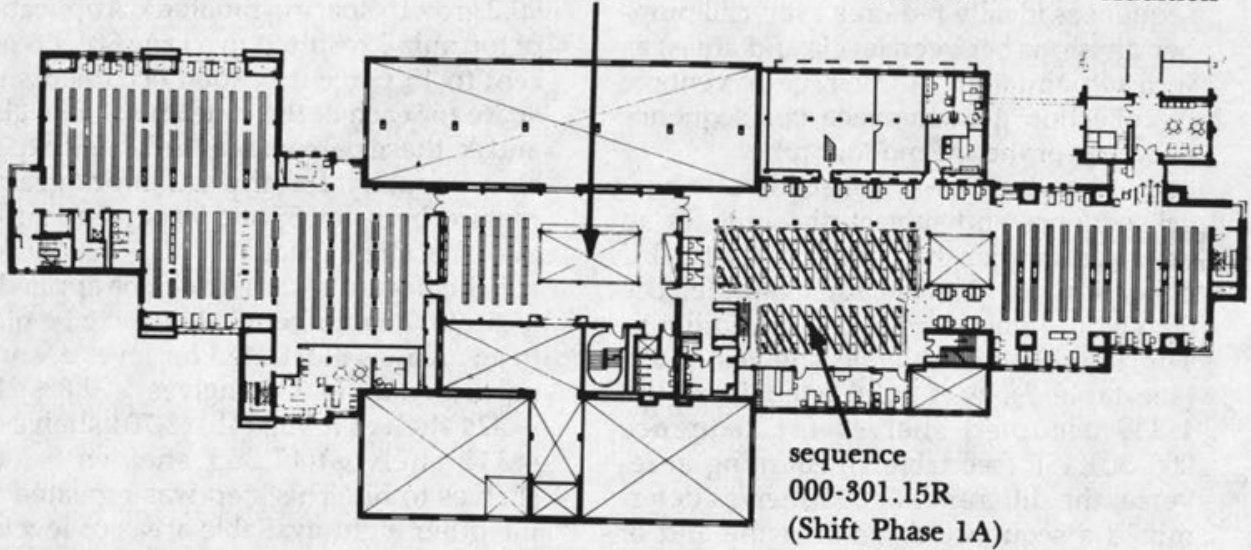

LEVEL 3

SOUTH

Addition
WEST

Pavilion
NORTH

Pavilion

Addition

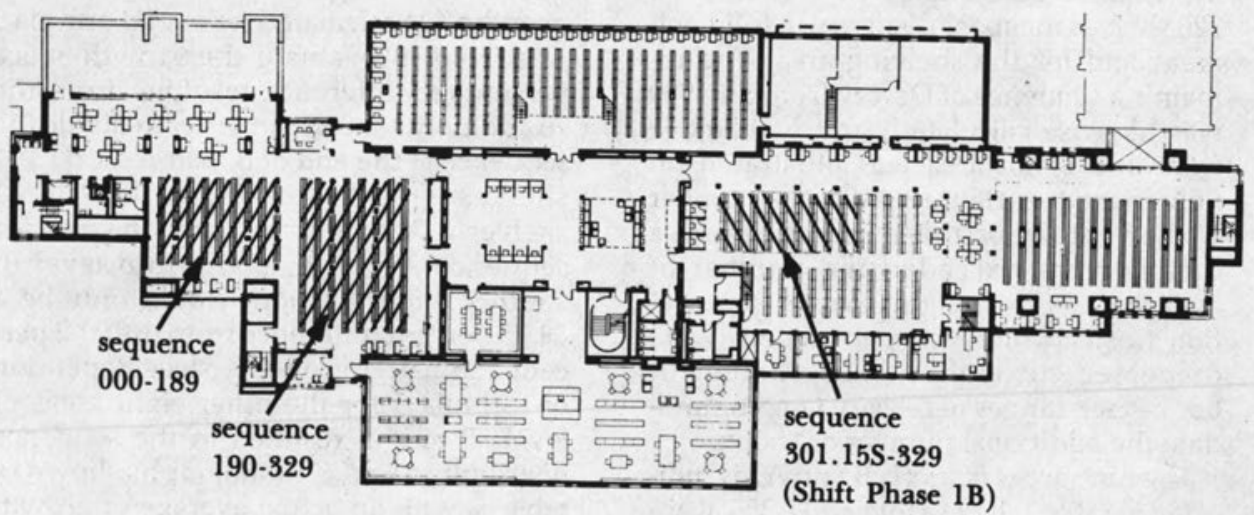

$\mathbb{M}$ previous sequence location VID permanent sequence location

FIGURE 1

Floor Plans illustrating movement of Dewey Decimil/Sequence 000-329 into Level 3 South.

*Figure 1 reproduced with permission from Cambridge Seven Associates, Inc., Cambridge, Massachusetts. 
five shelves per seven-shelf section would be occupied; an amended count of shelves at five per section minus the space for shelving areas was added in parentheses in table 2 .

For edification of the inexperienced in collection movement, too few or too many inches of space filled per thousands of shelves leads to chaos: either too much space and no books left to fill it or no space left and books left over. Also, books are continuously charged out and reshelved. To avoid miscalculation, all LC sequence divisions to be moved were measured by yardstick a couple of days prior to their movements. This measurement requires two people for two hours for 1,200 shelves of books.

Each measurement and the five-shelf per section count per area (see table 2 ) was employed in formula 6 to designate, as shown for level B, south pavilion, the exact number of inches to fill per shelf for each sequence: 15,080 inches $/ 1,160$ shelves $=13$ inches to fill per shelf for LC sequence A through B in level B, south pavilion. All LC sequences designated for levels B and A were so calculated. Cardboard sticks indicating how much to fill per area per level were used by student assistants moving the sequences. Formula 7, using the percentage obtained via formula 5 , may also be used to determine the amount to fill per shelf, but with books coming and going, it is far less accurate.

Data collected from previous shifts for the number of shelves of books moved per two-man team per hour were averaged to yield the standard formulas for the rates of man-hours per book movement, as provided at the bottom of table 5 . The figures for the estimated number of man-hours and time requirements for collectionmovement phasing were influenced, first, by the time of year when shifting occurred and, second, by collection characteristics, e.g., shelf adjustment and growth spacing for periodicals, folios, and newspapers; measurement requirements for LC monographs; and standard shelf-by-shelf movement.

During shifting phase one, initiated in January 1982 , the library employed as shifters eight college students who worked for Smith College Physical Plant Department; fortuitously, some of these students had previously worked as shifters in the library. In addition, eight Smith College students were also hired. Both groups, whose wages varied only slightly, worked an average of between thirty and thirty-five hours each week. Shifting phase one required seventeen days, or 866.5 man-hours, in January 1982 to move 9,483 shelves of books. At an average salary of $\$ 3.45$, the cost of labor to move phase one can be approximated at $\$ 2,989$.

The entire collection movement in three shift-phases was originally estimated for a twelve-month period, and consequently the estimates on manpower/time requirements were figured (and illustrated in table 5) for simultaneous moves in weekly periods throughout the year. In August 1981, shifting the collection was postponed from a September 1981 starting date to a January 1982 date during which a May or early-June collection-movement completion date was mandated. As with any plans for project completion, collection-movement planning and management must always maintain sufficient flexibility to adapt to unexpected circumstances affecting the development of the set of requirements for the moves.

The alteration in available time for the collection-movement completion was accompanied by unexpected areas of building availability during shifting phase one in January. This prompted a substitution of shifts from one originally scheduled phase to another. A revised estimate of manpower/time requirements preceded the implementation of shifting phases two and three. For budget requisition, to effect the movement of the remaining twothirds of the Neilson Library collection, an estimated 1,995 man-hours would be needed to move an estimated 16,551 shelves.

However, the revised estimate for manpower/time requirements meant first resolving how to consolidate and accelerate the remaining two-thirds of the twelvemonth operation of systematized bookmovement production into a four-month operation. How many student assistants were needed at six hours a week to accom- 
TABLE 5

ESTIMATED VERSUS ACTUAL MAN-HOUR TIME REQUIREMENTS OF NEILSON LIBRARY COLLECTION MOVEMENT PHASES

\begin{tabular}{|c|c|c|c|c|c|c|c|c|}
\hline $\begin{array}{l}\text { Shifting } \\
\text { Phase* }\end{array}$ & $\begin{array}{l}\text { Call No. } \\
\text { Sequence }\end{array}$ & $\begin{array}{l}\text { Shelves in } \\
\text { Sequence }\end{array}$ & $\begin{array}{l}\text { Est. } t \\
\text { Man- } \\
\text { Hours }\end{array}$ & $\begin{array}{c}\text { Actualł } \\
\text { Man- } \\
\text { Hours }\end{array}$ & $\begin{array}{c}\text { Men§ } \\
\text { per } \\
\text { Team }\end{array}$ & $\begin{array}{l}\text { Est. } \\
\text { Time }\end{array}$ & $\begin{array}{c}\text { Actual } \\
\text { Time } \\
\text { in Days }\end{array}$ & $\begin{array}{c}\text { Movement } \\
\text { Dates } \\
1982 \\
\end{array}$ \\
\hline 1. A. & $000-301.15 \mathrm{R}$ & 1,839 & 214 & 78 & $3-4$ & 3 wks & 3.5 & 4-7 Jan. \\
\hline & LC per HE-N & 1,148 & 140 & 152 & $3-5$ & 2 wks & 4.5 & 4-8 Jan. \\
\hline & locked stack & 154 & 18 & 19.5 & 3 & 1.5 days & 1 & 8 Jan. \\
\hline \multirow[t]{3}{*}{ B. } & $301.15 S-329$ & 586 & 70 & 78 & $3-4$ & $1 \mathrm{wk}$. & 2.5 & 7-12 Jan. \\
\hline & LC per $\mathrm{P}-\mathrm{Z}$ & 1,946 & 280 & 156 & $3-4$ & 3-4 wks. & 6 & 11-18 Jan. \\
\hline & LC per DS-HD & 952 & 150 & 80 & 2 & 2 wks. & 5 & 13-19 Jan. \\
\hline \multirow[t]{3}{*}{ C. } & $\mathrm{LC}$ folio $\mathrm{A}-\mathrm{Z}$ & 455 & 54 & 59 & $2-3$ & $1 \mathrm{wk}$. & 3 & 11-20 Jan. \\
\hline & Dewey oversize & 227 & 28 & 46 & $3-4$ & 4 days & 2 & 15-18 Jan. \\
\hline & theses & 35 & 2 & 2 & 2 & $1 \mathrm{hr}$. & $1 \mathrm{hr}$. & 18 Jan. \\
\hline \multirow{3}{*}{ D. } & newspapers & 322 & 36 & 26 & $3-4$ & 3.5 days & 2 & 19-20 Jan. \\
\hline & $600-799$ & 404 & 46 & 52 & 4 & 3.5 days & 2 & 20-21 Jan. \\
\hline & $\begin{array}{l}330-334.25 \\
973.72-999\end{array}$ & 514 & 60 & 38 & 2 & 4 days & 2.5 & 20-22 Jan. \\
\hline 65 & & $\begin{array}{l}425 \\
476\end{array}$ & $\begin{array}{l}48 \\
56\end{array}$ & $\begin{array}{l}45 \\
35\end{array}$ & $\begin{array}{l}2 \\
2-3\end{array}$ & $\begin{array}{l}3.5 \text { days } \\
4 \text { days }\end{array}$ & $\frac{3}{5}$ & 20-22 Jan. \\
\hline \multirow{5}{*}{ 2. A. } & $800-825 \mathrm{~F} .5$ & 753 & 90 & 82 & $2-3$ & $\begin{array}{l}4 \text { days } \\
7 \text { wks. }\end{array}$ & 7 & $\begin{array}{l}\text { 20-2b Jan. } \\
2-15 \text { Feb. }\end{array}$ \\
\hline & $830-849$ & 1,296 & 157 & 135 & $2-3$ & 13 wks. & 9 & $11-25 \mathrm{Feb}$. \\
\hline & $850-880.7$ & 729 & 87 & 72 & $2-3$ & 7 wks. & 4 & 16-22 Feb. \\
\hline & $940-949$ & 1,016 & 121 & 120 & $2-3$ & 10 wks. & 10 & 23 Feb.-15 Mar. \\
\hline & $345.13-599$ & 1,516 & 181 & 132 & $2-3$ & 15 wks. & 15 & 23 Feb.-22 Mar. \\
\hline \multirow[t]{4}{*}{ B. } & LC A-B & 494 & 54 & 42 & $2-3$ & 3.5 wks. & 4 & 3-8 Mar. \\
\hline & LC E-F & 329 & $\begin{array}{l}35 \\
87\end{array}$ & 30 & $2-4$ & 3 wks. & 2 & 8-9 Mar. \\
\hline & LC G-H & $\begin{array}{l}667 \\
599\end{array}$ & $\begin{array}{l}87 \\
70\end{array}$ & $\begin{array}{l}78 \\
72\end{array}$ & $\begin{array}{l}2-4 \\
2-4\end{array}$ & $\begin{array}{l}7.5 \text { wks. } \\
6 \text { wks. }\end{array}$ & $\begin{array}{l}7 \\
6\end{array}$ & $\begin{array}{l}\text { 9-16 Mar. } \\
\text { 15-23 Mar. }\end{array}$ \\
\hline & LC PS-Z & 549 & 61 & 54 & $2-4$ & 5 wks. & 6 & 15-23 Mar. \\
\hline \multirow[t]{4}{*}{ 3. A. } & $950-973.71$ & 557 & 66 & 60 & $2-3$ & 5 wks. & 4.5 & 16-23 Mar. \\
\hline & $880.8-939$ & 793 & 95 & 45 & & 8 wks. & 3 & 23-25 Mar. \\
\hline & LC per A-DR & 1,949 & 210 & 210 & $2-3$ & 17.5 wks. & 7 & 26 Mar. -4 Apr. \\
\hline & LC P-PN & 393 & 53 & 48 & 2 & 4 wks. & 4 & 23-30 Mar. \\
\hline B. & $\mathrm{LCK}-\mathrm{N}$ & 302 & 36 & 39 & $2-4$ & 3 wks. & 4 & 29Mar.-14 Apr.II \\
\hline & LC J & 466 & 70 & 61 & $2-4$ & 6 wks. & 5 & 30 Mar.-14 Apr.II \\
\hline & LC PQ-PR & 535 & 60 & 61 & $2-4$ & 1.5 wks. & 7 & 5-14 Apr. \\
\hline & 825F.6-829 & 901 & 108 & 48 & 4 & 9 wks. & 2 & 13-14 Apr. \\
\hline OTAL & $334.26-345.12$ & $\begin{array}{r}677 \\
24.004\end{array}$ & $\begin{array}{r}80 \\
2.923\end{array}$ & $\begin{array}{r}36 \\
2.2915\end{array}$ & 2 & 6.5 wks. & 3 & 12-14 Apr. \\
\hline & & & & & & & & \\
\hline
\end{tabular}

"Listed in order of movement implementation and grouped in simultaneous movement-phase clusters.

tThe rate of man-hours per book movement for shifting phase one is calculated as follows: 300 shelves per 35 hours per man per week; 600 shelves per 70 hours per 2 -man team per week. The rate of manhours per book movement for shifting phases two and three is calculated as follows: 50 shelves per 6 hours per man per week; 100 shelves per 12 hours per 2 -man team per week.

†Simultaneously increasing number of men per team and number of teams per shift decreased required time for collection movement phase.

$\S$ Number of teams working varied between 1 and 4 per shift.

IIThe time worked was between the given dates. 
plish the move by May 1982? And, given the incongruity of student schedules, how could an operation of this magnitude be successfully managed by the stack supervisor during daytime hours only, if large blocks of time were needed to really achieve necessary maximum effectiveness and efficiency in human resource utilization and book-movement production?

The answers derived from analysis of the chart for collection-movement phasing (see table 3), based on floor plans illustrating how many shelves of a sequence could move into what level and when they could move. As with all previous shifts of the collection, this analysis indicated that shifting phases were divisible into clusters of movement that could occur simultaneously. Books could move out of an area as books moved into that area; this principle of synchronized movement could be repeated in unison elsewhere in the library.

Since prior experience with student assistants proved that three hours was the maximum number of hours any student could fulfill in a large time block, it seemed logical to split a day of shifting into two three-hour periods, one in the morning, $8: 30$ to $11: 30$, and one in the afternoon, 1:00 to $4: 00$. The student assistants to be hired for the move were allotted $\$ 300$ per semester, or $\$ 3.35$ per hour for approximately fifteen weeks at six hours per week; and six hours a week could conveniently be divided into two three-hour time blocks. The semester would actually allow about 13.5 weeks of real movement time. The estimated 1,995 man-hours needed, divided by 13.5 weeks, produced a weekly need of approximately 147.7 man-hours, which then divided by six hours per student called for twenty-four students per week. At $\$ 3.35$ per hour, 1,995 hours required $\$ 6,683.25$. With knowledge that a minimum of three shifts was possible per morning and afternoon period, a preliminary time schedule of human resource utilization was charted for the production operation system of collection movement. This preliminary study confirmed the operational feasibility of twenty-four student assistants at six hours per week, a total of 144 man-hours per week, working on three three-hour shifts twice daily for four days.

Based on the estimate of manpower/ time requirements and the feasibility of the preliminary schedule for movement plan completion, the treasurer approved the appropriation of $\$ 6,700$ to the library for the employment of twenty-four student-assistant shifters for the remaining shift phases.

The Financial Aid Office recruited enough student assistants (most of whom were women) willing to "shift books" in either the three-hour morning or afternoon periods. Students reporting to the stack supervisor were interviewed and evaluated prior to hiring and scheduling for shift periods. To minimize the inevitability of voluntary termination of work by the students after the training period when shifting would be well under way, prospective student employees were apprised of the optimum work-load expectations, oral and written job description and specifications, and working conditions.

It was vital that students be able to coordinate their efforts by teamwork and maintain together a steady pace of people-book-truck movement. A book truck was available to demonstrate both method and work-load factors; the weight per loaded book truck averaged between 300 and 500 pounds, and truck movement over carpeting compounded its difficulty in manipulation. People with physical problems, e.g., back, arms, etc., or aversion to arduous physical labor, were not hired. Because the collection movement occurred post-construction/renovation, widespread dust covered both books and shelves; masks were provided for those willing to work in conditions possibly triggering occupational allergies, asthma, bronchitis, etc. Only three people voluntarily quit due to working conditions; another eight terminated because of conflicts with their academic work load. In a time when financial aid cutbacks threaten and campus jobs are at a premium, a provisional backup list of student-assistant shifters to fill vacant positions was no problem.

As expected, not every one of the twenty-four hired people could be ideally 
scheduled in each three-hour period, as shown in the preliminary time schedule; concessions were made to schedule as few as two or four people on some mornings and as many as ten or twelve in an afternoon. The schedule of shifts per threehour period fluctuated as the number of shift hours and man-hours per week increased or decreased and constant rescheduling ensued.

Each student per team had a numbered book truck, and trucks were always loaded and unloaded by truck number; each truck contained six shelves, with shelf numbers labeled 1 through 6 . This organization made possible two people's simultaneously loading and unloading for Dewey shelf-by-shelf shifts. Some shifts, Dewey and LC monographs, permitted simultaneous forward and backword movement into an area. Such doubling up of teams to relocate a sequence simultaneously increases efficiency and decreases the time required for a shift and accounts for the differences between estimated versus actual man-hours listed in table 5 .

Other shifts required more time than estimated. In the LC periodicals, for example, shelf adjustment, growth-space determination, and distance between moving points decreased the efficiency of the standardized book-movement rates (see table 5). Each periodical title, most in bound volumes of varying width and height, required readjusting the pre-set seven-shelf sections, to be accommodated; simultaneously, fifteen years' growth space per title was figured by counting how many volumes per year fit on a shelf. Some titles required adjusting as many as ten empty shelves for growth space, while other titles needed only one shelf. Additionally, the distance round trip for periodical movement was just under a quarter-mile.

The estimated versus actual man-hours required for the relocation and distribution of the LC monographs from three areas into nine areas shows little variation, despite having to fully load each booktruck shelf and unload onto stack shelves according to the predetermined stick measurement of inches per shelf. The student assistants were constantly reminded of the repercussions as a result of deviating an inch over or under the required length to fill per shelf. At times, a twenty-minute lack of supervision did result in having to reshift a couple of overfilled or underfilled ranges; however, time lost for the error required only half the time to rectify.

There were only three downtime days with no elevator use, during which time shelf adjustment, shelf disassembly and storage, dusting, and book-end distribution occurred. Storage for books to be reshelved was solved by creating an "emergency shelving area" in the area projected to be last occupied in shift phase three; books were relocated to the permanent shelving areas in late March.

Shift phases two and three required $\$ 4,773.75$, of the appropriated $\$ 6,700$ budget, for 1,425 man-hours to move the estimated 14,521 shelves of books. The entire collection of approximately 25,000 shelves (682,810-plus volumes) was moved and expanded into 33,500 shelves of those 40,509 available, during a threeand-a-half-month period over a total of fifty-nine days. Overall, the standardized book-movement rates (see table 5 , bottom) for the operation of producing booktruck-people movement functioned effectively for compiling budgetary projection requirements. In retrospect, time estimates for movements appear generous. However, the shifters accomplished as much as was demanded of them and, had they not been constrained to perform, the movement times might have been longer.

The book-movement rates and production system operation were functionally efficient in that fewer man-hours and dollars were actually used for the shift phases. Shift phases two and three, for example, used 570 fewer hours and $\$ 1,926.26$ less than estimated. Excluding the stack supervisor's hours involved, the entire collection movement cost approximately $\$ 7,762$, or about $23 €$ per shelf. The cost and quality of the student assistants was most efficient, and the time of year, budget, and knowledge of the collection and building availability made student assistants a most economical means of labor. 
Often, the economics of a collection movement are at first the determining factor influencing the method chosen for movement, and are lastly an indicator of the method's effectiveness and efficiency. It cannot be forgotten that to be effective and efficient the method must also be managed, and that management entails fluency in all its contiguous functions: decision making, planning, organizing, staffing, controlling, communicating, and directing.

The decision-making process must account not only for the method of movement, but also for the job specifications of the person to be placed in charge. A person knowledgeable of the collection in total is a most likely candidate; that person should be adept in group scheduling and coordination and in human resource utilization. If the supervisor in charge will also be the planner, then he or she should be skilled in mathematical reasoning, conceptualization, and problem solving. Additional knowledge of the factory concept of a production operation system is an asset enhancing smooth systemization of several simultaneous movement operations. Planning the movement must take into account construction time schedule, interim collection storage, time/manpower requirements for budget requisition, job definition, and the type of human resources to be allocated for collection movement.
Organizing the movement design requires floor plans and counts of available book-stack shelves; statistics on the number of currently occupied shelves according to collections and locations; a time schedule of building area availability; and mathematical formulas for calculating book dispersal at the final stage of movement. Staffing involves the recruitment, hiring, and training of the human resources for the jobs defined for the collection movement. A backup list of employee replacements can supplement loss through voluntary or involuntary termination. The controlling, communicating, and directing involves manpower training and supervision. Each task assignment necessities written and/or verbal communication of job tasks, procedure demonstration, safety regulations, performance evaluation of progress, and disciplinary action.

Finally, there are many unforeseen factors affecting planning and implementation of a collection movement. There may always be changes in proposed construction schedules and building design that can considerably affect daily scheduled movements. In conclusion, the success of an entire collection movement demands constant and accurate supervision in a high-pressure environment, especially when both budget and time constraints are imposing factors.

\section{REFERENCES}

1. A. E. Lumb, "Moving an Academic Library," Journal of Librarianship 4:253 (Oct. 1972).

2. Ibid., p. 253.

3. William H. Kurth and Ray W. Grim, Moving a Library (New York and London: Scarecrow Pr., 1966), Foreword, unpaged.

4. Ibid., p. 15.

5. Ibid., p. 15.

6. Ibid., p. 192.

7. Peter Spyers-Duran, Moving Library Materials (Chicago: American Library Assn., 1965).

8. Matt Roberts, "Some Ideas on Moving a Book Collection," College \& Research Libraries 27:103-8 (Mar. 1966); Donald P. Hammer, "Operation Book Shift," College \& Research Libraries 21:393-94 (Sept. 1960).

9. Appendix A is based on Florian Cajori and Letitia R. Odell, Elementary Algebra (New York: Macmillan, 1915), p.1-2, 4. 


\section{APPENDIX A: ELEMENTARY ALGEBRAIC PRINCIPLES}

1. The signs of operation used in arithmetic are also used in algebra: + for addition, $x$ for multiplication, $\div$ for division.

2. In arithmetic, and also in algebra, division is frequently expressed in the form of a fraction: $4 \div 2=2$ or $4 / 2=2$.

3. Any combination of numbers, letters, and symbols of operation, which represents a number, is called an algebraic expression:

$a=4, b=2$ then $a / b=c$ or $c=2$

4. In arithmetic, it is customary to use abbreviations, such as $\mathrm{ft}$. for foot, in. for inches, and so on. In algebra the practice of using abbreviations is carried much further; the same letter may be used for different things in different problems.

5. The letter $x$ is used extensively to designate a number that is unknown at the outset, but that is to be determined by solution of the problem at hand. The meaning of the letter must be made plain in each problem. To avoid confusion, no letter should stand for two different things in the same problem.

6. An equation, expressing an equality, is formed, which enables one to ascertain the value of the unknown number.

\section{APPENDIX B}

\section{Formula 1}

Problem: A library's collection comprises several collection types, e.g., Dewey decimal classed books, Library of Congress monographs, etc., each of which must be considered for placement on different floors and areas of a renovated library with newly constructed additions to the building. Given the collections, each represented by the number of shelves they occupy, what areas under consideration will make the most efficient use of space to be occupied? What percentage of that space would be occupied? Let $a=\#$ of shelves occupied; $b=\#$ of shelves to be occupied; $x=\%$ of space to be occupied in area under consideration. Therefore- $(a / b)=x ;$ If $x=(x / 100)$, then $(a / b)=(x / 100)$ and $(a / b)$ $\times(100 / 1)=(x / 100) \times(100 / 1)$ and $(a \times 100) / b=x$. Replacing the letter symbols with the number of shelves they represent in formula 1, as given in text on page 223 for feasibility of options study 1 , it follows: (a) $(11,989 \times 100) / 17,801=67.35 \%$ of space occupied for Dewey collection and (b) $(4,334 \times 100) / 9,121=47.5 \%$ of space occupied for LC collection.

Formula 2

Problem: If the Dewey collection was to be placed in the area under consideration used in formula 1, how many inches must be ideally filled per 35-inch shelf in order that all shelves are occupied with some books? How many inches would be ideally filled for the LC collection to be distributed throughout the area under consideration and used in formula 1 ? Let $n=$ number for percentage, and $x=$ inches to fill per shelf, then $(n \times 35) / 100=x$. Given the percentages of space occupied (answers from formula 1), $67.35 \%$ for Dewey and 47.5 for LC, then: $(67.35 \times 35) / 100=x$ OR $x=23.5725$ inches to fill per shelf of Dewey and $(47.5 \times 35) / 100=x$ OR $x=16.625$ inches to fill per shelf of LC. If percentage conversion is used, the formula is: $\% \times 35=x$. Example: $67.35 \%=67.35 / 100$ or .6735 and $.6735 \times 35=$ $x$ or 23.5725 .

Answer Analysis

For the examples given in use of formulas 1 and 2, it was shown that the Dewey collection, if put into the area under consideration, would occupy only 67.35 percent of total available space; to occupy the other $(100-67.35=32.65)$ near 33 percent, 23.5 inches per shelf would be filled if books were distributed to occupy 67.35 percent of space on each shelf. The latter would entail spreading out a closed, nongrowing, or shrinking collection.

Since all shelves are 35 inches wide, the shelves for the LC collection would be just less than half full, enough growth space for about four years. Moving the entire collection in another five years would defeat the purpose in building expansion. A repetition of equations for each optional placement of collection types will answer what collection, given its characteristics, will be more suitably housed in areas under consideration. 